\title{
Uma comparação entre as análises de Antonio Candido e Roberto Schwarz sobre José de Alencar
}

\author{
Ana Karla Canarinos*
}

\section{RESUMO}

Este trabalho objetiva mapear os posicionamentos de Antonio Candido e Roberto Schwarz sobre a produção de José de Alencar, mais especificamente o romance Senhora. Para tanto, serão considerados os ensaios "Os três alencares", de Antonio Candido, publicado em Formação da literatura brasileira (1959); e "A importação do romance e suas contradições em Alencar", de Roberto Schwarz, publicado em Ao vencedor as batatas (1977). Ambos os críticos são comumente relacionados pela crítica por compartilharem do mesmo arsenal teórico e metodológico, no entanto, as análises sobre José de Alencar revelam diferenças importantes sobre a concepção de modernidade literária dos autores. Nesse sentido, a partir da comparação entre os dois textos críticos sobre a produção alencariana, este artigo pretende debater as tensões e descontinuidades entre o posicionamento de Antonio Candido e Roberto Schwarz.

Palavras-chave: Teoria literária. Crítica literária brasileira. José de Alencar. Roberto Schwarz. Antonio Candido.

* Universidade de Campinas (Unicamp). Mestre em estudos lusófonos pela Université Lumiere Lyon 2, França. Doutoranda em Teoria e História Literária na UNICAMP. Bolsista FAPESP. 


\title{
A Possible Relation Between Antonio Candido And Roberto Schwarz Analysis on José De Alencar
}

\begin{abstract}
This work aims to map the positions of Antonio Candido and Roberto Schwarz on the production of José de Alencar, more specifically the novel Senhora. For that, the essays "Os três alencares" by Antonio Candido, published in Formação da literature brasileira (1959), will be considered; and "A importação do romance e suas contradições em Alencar", by Roberto Schwarz, published in Ao vencedor as batatas (1977). Both critics are commonly criticized for sharing the same theoretical and methodological arsenal, however, analyzes of José de Alencar reveal important differences about the authors' conception of literary modernity. In this sense, from the comparison between the two critical texts on Alencarian production, this article intends to discuss the tensions and discontinuities between the positioning of Antonio Candido and Roberto Schwarz.
\end{abstract}

Keywords: Literary criticism. Brazilian literary criticism. José de Alencar. Roberto Schwarz. Antonio Candido. 
Antonio Candido e Roberto Schwarz têm o mesmo método de crítica literária - o método dialético, que compreende as intrincadas relações entre processo social e forma literária. Inclusive, Antonio Candido, em textos importantes como a introdução do Formação da literatura brasileira e a palestra proferida no II Congresso de Crítica e História Literária, realizado em Assis (1961) e, posteriormente, publicada em Literatura e sociedade (1965) sob o título de "Crítica e Sociologia", delineou os pressupostos do método dialético na análise literária. Nesse texto, um dos pilares do desenvolvimento do pensamento dialético de Antonio Candido, o crítico apresenta as duas vertentes dicotômicas de análise literária: de um lado, a análise em que "procurava-se mostrar que o valor e o significado de uma dependiam de ela exprimir ou não certo aspecto da realidade" (CANDIDO, 2000, p. 4); de outro, a análise em que se procura mostrar que a matéria de uma "obra é secundária, e que a sua importância deriva das operações formais postas em jogo, conferindo-lhe uma peculiaridade que a torna de fato independente de quais condicionamentos, sobretudo social" (CANDIDO, 2000, p. 4). A crítica integrativa de Candido está justamente na junção dialética entre aspectos formais da literatura e processo social:

Hoje sabemos que a integridade da obra não permite adotar nenhuma dessas visões dissociadas; e que só a podemos entender fundindo texto e contexto numa interpretação dialeticamente íntegra; em que tanto o velho ponto de vista que explicava pelos fatores externos, quanto o outro, norteado pela convicção de que a estrutura é virtualmente independente, se combinam como momentos necessários do processo interpretativo. Sabemos ainda, que o externo (no caso, o social) importa, não como causa, nem como significado, 
mas como elemento que desempenha um certo papel na constituição da estrutura, tornando-se, portanto, interno. (CANDIDO, 2000, p. 4).

Na mesma linha depensamento, na introdução da Formação, a partir dos conceitos de sistema literário e acumulação literária, Candido definiu a ambivalência e a fidelidade dupla (local e universal) que rege a vida intelectual no Brasil, ou seja, alternância, complementariedade, divergência e equilíbrio entre a realidade local e a lógica europeia. O conceito de sistema literário, portanto, era concebido tendo em vista a integração de três elementos: autor, obra e público, visando integrar análise estética e social como estratégia de reconfigurar o sentimento de "dualidade" que acompanhou a sociologia e a crítica literária até então:

[...] convém principiar distinguindo manifestações literária, de literatura propriamente dita, considerada aqui um sistema de obras ligadas por denominadores comuns, que permitem reconhecer as notas dominantes duma fase. Estes denominadores são, além das características internas (línguas, temas, imagens), certos elementos de natureza social e psíquica, embora literariamente organizados, que se manifestam historicamente e fazem da literatura aspecto orgânico da civilização. (CANDIDO, 2012, p. 25) ${ }^{2}$

1 Paulo Arantes em O sentimento da dialética (1992) caracteriza Antonio Candido como o crítico que dá o balanço das oposições dualistas que regem a experiência brasileira, situando os termos inimigos no interior de um mesmo movimento. Segundo Paulo Arantes, Antonio Candido é o crítico dialético por excelência, diferentemente do dualismo enquanto sentimento das elites de Sílvio Romero, José Veríssimo e Joaquim Nabuco, até o dualismo refletido teoricamente por especialistas advindos da história, da sociologia ou mesmo da economia, como Ignácio Rangel, Celso Furtado e Raymundo Faoro.

2 Estudos como o de Leopoldo Waizbort em A passagem do três ao um (2007) e de Paulo Arantes em O sentimento da dialética (1992) e O sentido da formação (1997) localizam em Candido o momento da maturação da crítica literária brasileira no seu desejo de ter uma crítica 
De sua parte, Roberto Schwarz assinala a forte influência do pensamento dialético de Antonio Candido na formulação da sua crítica sobre Machado de Assis: "Devo uma nota especial a Antonio Candido, de cujos livros e pontos de vista me impregnei muito" (SCHWARZ, 2000, p. 13). Mais tarde, já no final da década de 1990, Roberto Schwarz volta a ressaltar a influência de Antonio Candido na sua formação de crítico literário, em uma entrevista para a Folha de S. Paulo. ${ }^{3}$ Assim como Schwarz assume a influência do pensamento crítico de Candido, poderíamos dizer que Antonio Candido sempre esteve impregnado com distanciamento crítico do pensamento de Sílvio Romero. No seguinte trecho de Formação, o crítico deixa clara a importância de Romero para o desenvolvimento do seu trabalho como crítico e teórico:

Desejo, aqui, mencionar um tipo especial de dívida em relação a duas obras bastante superadas, que paradoxalmente, pouco ou nada utilizei, mas devem estar na base de muitos pontos de vista, lidas que foram repetidamente na infância e na adolescência. Primeiro, a História da literatura brasileira de Silvio Romero, cuja lombada vermelha, na edição Garnier de 1902, foi bem cedo uma das minhas fascinações na estante

literária especializada. $\mathrm{O}$ autor reconhece um processo de acumulação intelectual (desde as críticas literárias de Machado de Assis, Joaquim Nabuco, José Veríssimo, Sílvio Romero, Mário de Andrade, Oswald de Andrade) absorvido por Antonio Candido na tentativa de síntese da formação da tradição literária brasileira, colocando-o numa posição análoga à de Machado, só que no campo da crítica. Waizbort localiza a crítica do autor de Formação como o momento de superação da crítica impressionista e de formulação de um conceito específico para pensar a literatura brasileira.

3 "Nesse mesmo ano, houve um congresso de crítica em Assis, no qual o Antonio Candido fez uma comunicação que para mim foi decisiva. Nela, ele anunciava mais ou menos o programa crítico da fase dele posterior à Formação da literatura brasileira. A comunicação foi publicada em Literatura e sociedade, com o título 'Crítica e Sociologia"'. (BARROS E SILVA, 1999, p. 57). 
paterna, tendo sido dos livros que mais consultei entre os dez e quinze anos, à busca de excertos, dados biográficos e os saborosos julgamentos do autor. Nele estão, provavelmente, as raízes do meu interesse pelas nossas letras. (CANDIDO, 2012, p. 13).

Reflexões como essas permitem pensar uma linha genealógica da crítica literária de cunho sociológico no Brasil: Sílvio Romero, Antonio Candido e Roberto Schwarz. Em O método crítico de Sílvio Romero, Antonio Candido realiza um estudo detalhado dos acertos e desacertos do crítico, apontando outros encaminhamentos para a crítica sociológica e para a relação entre literatura e sociedade. $\mathrm{O}$ principal problema de Silvio Romero, segundo Candido, é o modelo de crítica literária "positivista e, em geral, naturalista" (CANDIDO, 2006, p.165), uma vez que ele, ao contrário, pratica uma crítica dialética, com base na análise imanente do texto literário.

Em Brigada ligeira e outros escritos, Antonio Candido assume que, em $\mathbf{O}$ método crítico de Silvio Romero, formulou seus pontos de partida teóricos, cujo desdobramento se daria na sua segunda fase, que se desenvolveu a partir de outras influências, como "de um lado a Antropologia social inglesa (Malinowski, Radcliff-Brown) e de outro, as ideias críticas de T.S Eliot e o New Criticism americano" (CANDIDO, 1992, p. 232). Ou seja, o crítico movimenta a dialética da continuidade e da ruptura diante da obra de Silvio Romero, seu predecessor, movimento dialético que se dará de maneira silenciosa na relação entre Antonio Candido e Roberto Schwarz, como veremos a seguir.

Sobre Antonio Candido, Roberto Schwarz jamais escreveu algum texto apontando as descontinuidades de algum ponto de vista de Formação diretamente. Em Sequências brasileiras - 
Uma comparação entre as análises de Antonio Candido e Roberto Schwarz sobre José de Alencar

em textos como "Saudação honoris causa", "Sobre Formação da literatura brasileira", "Adequação nacional e originalidade crítica" e "Os sete fôlegos de um livro" -, Roberto Schwarz não apresenta um tom de divergência explícito em relação ao mestre. Em "Adequação nacional e originalidade crítica", Schwarz analisa o texto "De cortiço a cortiço" de Antonio Candido, publicado na década de 1970, e destaca na análise do crítico a "dimensão que escapava às leituras estruturalistas então em voga" e a "necessidade do trânsito entre a análise estética e a reflexão histórica" (SCHWARZ, 1999, p. 78). A valorização da produção de Antonio Candido e o seu caráter pioneiro nas relações entre forma literária e processo social é enfatizado constantemente por Roberto Schwarz, em cujo centro aparece Candido como o sujeito que promove a dialética na análise literária:

Com propósito apenas indicativo, a parte final do ensaio aproxima $\mathbf{O}$ cortiço de L'Assommoir e de Memórias de um sargento de milícias, obras que o Autor estudou no mesmo período. O confronto cria um espaço de diferenças poderosamente sugestivas, entre, por exemplo, o significado sobretudo social da pobreza em Zola (Naturalismo europeu) e seu significado mais alegórico-nacional em Aluísio (Naturalismo brasileiro); ou entre a dialética de ordem e desordem num universo quase sem trabalho, como é o caso no Sargento de milícias, e a dialética do espontâneo e do dirigido num mundo comandado por lucro, trabalho, competição como é o caso n'O cortiço. [...]. Daí o caráter discreto, mas resolutamente pioneiro dos ensaios de Antonio Candido, obrigado a prover ele mesmo a história, a sociologia e a psicologia social necessárias à plenitude de suas observações no plano formal. (SCHWARZ, 1999, p. 51-53, grifo nosso).

Há diferença na maneira de formalização da ruptura de Antonio Candido com a produção do mestre Silvio Romero 
e da ruptura de Roberto Schwarz com a produção do mestre Antonio Candido. Neste ensaio, não pretendemos rastrear as diferenças entre as duas relações de mestre-discípulo, ainda que a linhagem de cunho sociológico seja perceptível nesses três críticos. Roberto Schwarz claramente leva a cabo a crítica dialética de Antonio Candido na sua atividade de crítico literário, entretanto, o objetivo principal deste ensaio está justamente na descontinuidade silenciosa que se encontra nas entrelinhas, no tom e também nas diferentes influências marxistas de ambos os críticos, podendo ser mapeada, por exemplo, nas análises que efetuaram da produção de José de Alencar.

\section{Duas leituras de José de Alencar}

Em 1959, Antonio Candido publica "Os três alencares" na Formação da literatura brasileira, obra que ocupa um lugar de destaque nos estudos alencarianos do período. A partir do reconhecimento de três Alencares, Antonio Candido apresenta uma nova forma no período de organização da obra de José de Alencar. O primeiro corresponderia ao "Alencar dos rapazes", com os romances $O$ guarani, As minas de prata e $O$ sertanejo, caracterizados pela "aspiração de heroísmo e o desejo eterno de submeter a realidade ao ideal." (CANDIDO, 2012, p. 223). O segundo Alencar é o autor das "mocinhas" (CANDIDO, 2012, p. 223). Trata-se dos romances que, centralizados geralmente na figura feminina, seguem a fórmula narrativa da complication sentimentale: os protagonistas se deparam com um obstáculo para a realização de seu amor e, após uma série de eventos, tudo se esclarece e o casal efetiva o enlace amoroso. O Alencar das mocinhas é, segundo o historiador, "criador de mulheres 
Uma comparação entre as análises de Antonio Candido e Roberto Schwarz sobre José de Alencar

cândidas e moços bons, que dançam aos olhos do leitor uma branda quadrilha ao compasso do dever e da consciência, mais fortes que a paixão." (CANDIDO, 2012, p. 539). Por último, “É o Alencar que se poderia chamar dos adultos, formando uma série de elementos pouco heroicos e pouco elegantes, mas denotadores dum senso artístico e humano que dá contorno aquilino a alguns dos seus perfis de homem e de mulher" (CANDIDO, 2012, p. 540). Esse último Alencar atravessa e complementa os dois anteriores, uma vez que Antonio Candido aponta certas ousadias do autor como a cena da bofetada em Diva; a relação conturbada de Manuel Canho com os homens e os cavalos em $O$ gaúcho; o fetiche de Horácio de Almeida por um pé em A pata da gazela e a presença de um louco epilético em Til.

Antonio Candido destaca, nesse sentido, a recorrência de alguns procedimentos narrativos presentes na ficção de José de Alencar: 1) "a diferença de condições sociais é uma das molas da ficção"; 2) o comportamento dos protagonistas diante de suas amadas, "que oscila entre o acachapamento e a altiva reserva"; 3) "o papel decisivo do passado para a compreensão dos conflitos no presente"; e 4) "a presença ostensiva do contraste de uma situação, de uma pessoa ou de um sentimento" (CANDIDO, 2012, p. 542544). Nesse último item, Antonio Candido aponta pelo menos duas dicotomias que o romance romântico estabelece: 1) entre o bem e o mal; 2) equilíbrio fisiológico e psíquico: “sentimos em Alencar a percepção complexa do mal, do anormal ou do recalque, como obstáculo à perfeição e elemento permanente na conduta humana." (CANDIDO, 2012, p. 543). Por isso, talvez seja possível afirmar que Antonio Candido é o primeiro crítico a reconhecer que é Alencar, e não Machado de Assis, o precursor das pesquisas psicológicas no romance brasileiro: 
Há, porém, certa injustiça em atribuir-lhe [a Machado de Assis] a iniciativa das análises psicológicas, encarando toda a ficção anterior como um conjunto ameno, superficial e pitoresco. Na verdade ele foi, sob vários aspectos, continuador genial, não figura isolada e literariamente sem genealogia no Brasil, tendo encontrado em Alencar, além da sociologia da vida urbana, sugestões psicológicas muito acentuadas no sentido da pesquisa profunda. [...] Senhora, mas sobretudo Lucíola, demonstram agudo senso da complexidade humana, nem foi por acaso que o Conselheiro Lafayette qualificou Lúcia e Diva de "monstrengos morais", e Araripe Jr. não soube explicá-las senão encaixando-as pejorativamente em uma enfermaria. Há em Alencar não apenas um leitor de Chateaubriand, Lamartine e Walter Scott, mas um apaixonado balzaquiano que se tem menosprezado. (CANDIDO, 2012, p. 529).

O ensaio de Roberto Schwarz "A importação do romance e suas contradições em Alencar" (1977) constrói, por sua vez, uma complexa reflexão crítica, que tem como ponto de partida a análise dialética de Antonio Candido em Formação da literatura brasileira. $\mathrm{O}$ centro da argumentação de Schwarz aponta para o fato de que "nossa imaginação fixara-se numa forma cujos pressupostos, em razoável parte, não se encontravam no país, ou encontravam-se alterados" (SCHWARZ, 2012a, p. 35). Ou seja, o descompasso resultante desta combinação desconjuntada, e que Antonio Candido já havia notado, é formulado pelo crítico nos seguintes termos:

A notação verista, que dá estatuto e curso literário a elementos de nosso mundo cotidiano, entra em choque com o enredo, o verdadeiro princípio da composição, que tem a sua mola nas ideologias do destino romântico, em versão realista para o Alencar do romance urbano de mais força. Ora, como já vimos o nosso cotidiano 
regia-se pelos mecanismos do favor, incompatíveis - num sentido que precisaremos adiante - com as tramas extremadas, próprias do Realismo de influência romântica. Submetendo-se ao mesmo tempo à realidade comezinha e à convenção literária, o nosso romance embarcava em duas canoas de percurso divergente, e era inevitável que levasse alguns tombos de estilo próprio, tombos que não levaram os livros franceses. (SCHWARZ, 2012a, p. 41).

A crítica de Schwarz acerca do tom em Senhora ilustram bem a configuração, no âmbito ficcional, da dualidade entre a forma literária e o nosso processo social. Roberto Schwarz observa que o tom no romance é variável: na periferia o registro é mais rebaixado enquanto no registro de Aurélia e da classe superior, onde se encontra a "mocidade núbil", há a intensificação do registro elevado, sobretudo em comparação à periferia.

Ou seja, a separação entre centro e periferia social está presente não apenas no tom do romance, mas também na natureza social da matéria. As personagens periféricas pertencem a "uma esfera singela e familiar" em que a ação gira em torno de vícios, virtudes e mazelas, sem que essa esfera seja posta em questão, "legitimada que está pela natural e simpática propensão das pessoas à sobrevivência rotineira." (SCHWARZ, 2012a, p. 43). Nos personagens subalternos ocorre a suspensão de uma "intenção universalista e normativa, própria da prosa românticoliberal da faixa de Aurélia": "Seu mundo é o que é, não aponta para outro, diferente dele, no qual se devesse transformar" (SCHWARZ, 2012a, p. 44). Por outro lado, as personagens centrais, pertencentes ao meio burguês e valores universais como o amor, o cálculo do dinheiro, a hipocrisia e as aparências, a ação é movida pelo poder do dinheiro. Sob este aspecto, a linguagem encontra-se saturada de implicações morais, pois a hipocrisia 
das relações combina-se, em um esforço corretivo, "à pretensão de exemplaridade própria desta esfera, e à espontaneidade, própria ao sentimento romântico" (SCHWARZ, 2012a, p. 43). A seriedade que toma conta do centro do romance, bem ao contrário do que ocorre na periferia do romance, funciona como a problematização do romance burguês cujo modelo estaria em Balzac:

É neste segundo estilo carregado de princípios, polarizado pela alternância de sublime e infâmia, que ele se filia à linha forte do Realismo de seu tempo, ligada, justamente, ao esforço de figurar o presente em suas contradições; em vez de dificuldades locais, as crispações da civilização burguesa. (SCHWARZ, 2012b, p. 44).

O tom sério do romance, segundo Schwarz, funciona como "pretensioso"e "descabido", principalmente pelo seu convívio com a parte periférica da composição. É justamente na sobreposição entre esses dois planos que aparece a presença da dualidade entre o processo social, que se impõe como matéria e condição de verossimilhança, e os pressupostos da forma literária. Segundo Roberto Schwarz, o desacerto literário em Senhora reside no descompasso entre a predominância formal - no tom, no assunto e nos procedimentos - e a matéria local. Ou seja, o deslize estético do romance estaria na equivocada escolha das personagens que não funcionam como a síntese social de uma classe e que, pelo equívoco, deslocaria os recursos formais (tom, enredo etc.), dando certo efeito de infundado à narrativa, nestes termos: "A dura dialética moral do dinheiro se presta ao galanteio da mocidade faceira, mas não afeta o fazendeiro rico, o negociante, as mães burguesas, a governanta pobre, que se orientam pelas regras do favor ou da brutalidade simples". (SCHWARZ, 2012b, p. 46-47). 
Uma comparação entre as análises de Antonio Candido e Roberto Schwarz sobre José de Alencar

Nessa última passagem, Roberto Schwarz aprofunda a incongruência estrutural do romance, mostrando que ela não se reduz apenas à escolha das personagens, mas também à dialética moral do dinheiro. Ao fazer da dialética moral do dinheiro o centro do romance em torno do qual giram Aurélia e Fernando, Alencar não só desconecta as personagens periféricas do desenvolvimento narrativo, como também aponta que a síntese de nosso processo social estaria localizada em um conflito "da forma-mercadoria" e "do dinheiro como nexo elementar do conjunto da vida social", em um país ainda imerso na lógica escravocrata. A dialética do dinheiro, atrelado ao problema do descompasso das personagens centrais e periféricas geram a falta de unidade na composição, transformando o romance em algo desconjuntado, confinando-o "nos limites da frivolidade". (SCHWARZ, 2012b, p. 45).

\section{Divergências entre Antonio Candido e Roberto Schwarz}

As análises de Antonio Candido e Roberto Schwarz seguem o mesmo pressuposto dialético entre forma literária e processo social. Entretanto, poderíamos apontar pelo menos dois aspectos em que as análises dos dois críticos divergem: a análise da dualidade entre particular e universal no romance Senhora e o tom da crítica ao progresso. Nesse sentido, algumas teses de A teoria do romance, de Lukács, e da Dialética do Esclarecimento, de Theodor Adorno, são importantes para refletir sobre as diferentes soluções propostas pelos dois críticos na análise de José de Alencar. A relação de Antonio Candido com Lukács é mais direta do que a do seu discípulo, Roberto Schwarz, cuja produção também recebe forte influência da Escola de Frankfurt. 
No prefácio de Um mestre na periferia do capitalismo (2000), Schwarz afirma a influência Lukács, Brecht, Benjamin e Adorno no desenvolvimento de sua produção, reconhecendo também a contradição existente entre esses autores da crítica marxista e a centralidade do método dialético como um denominador comum entre esses teóricos (SCHWARZ, 2000, p. 13). Em entrevista à Eva Corredor (SCHWARZ, 2002, p. 34), Schwarz afirmou ter buscado certa complementariedade entre os autores dessa tradição marxista contraditória, sobretudo entre Lukács e Adorno. Entretanto, em "Sobre Adorno", Schwarz afirma que Adorno e sua crítica negativa tiveram um peso maior na sua formação como crítico literário. (SCHWARZ, 2012b, p. 44-52). Nesse sentido, a aproximação do teórico frankfurtiano é decisiva na divergência entre Antonio Candido e Roberto Schwarz.

A recepção de Lukács, por parte de Antonio Candido e de Roberto Schwarz, ocorre principalmente pela A teoria do romance, denominada pela crítica como parte integrante da etapa do "Jovem Lukács", juntamente com A alma e as formas (1908) e História e consciência de classe (1923). Por conta disso, é possível considerá-la uma obra controversa, justamente por ter sido renegada pelo próprio autor em 1962, período de publicação da sua Estética (1970), e por ter sido resgatada por outros comentadores. Segundo a teoria do romance, a forma épica, para consumar-se, pressupunha a constituição de uma totalidade capaz de superar os limites entre indivíduo e mundo, e a mais antiga realização dessa totalidade podia ser encontrada na epopeia grega. No período helenístico, "o círculo em que vivem metafisicamente os gregos é menor do que o nosso" (LUKÁCS, 2009, p. 30); já na modernidade, "o nosso mundo tornou-se infinitamente grande e, em cada recanto, mais rico em dádivas 
e perigos que o grego, mas essa riqueza suprime o sentido positivo e depositário de suas vidas". (LUKÁCS, 2009, p. 31). Com a fragmentação do mundo moderno, a totalidade torna-se problemática, uma vez que a "totalidade do ser só é possível quando tudo já é homogêneo, antes de ser envolvido pelas formas; quando as formas não são uma coerção". (LUKÁCS, 2009, p. 31). Ou seja, o declínio da epopeia apontava para a própria dificuldade da forma de continuar representando o mundo pleno de sentidos, o que abre caminho para o romance, a forma narrativa do mundo moderno, do herói problemático, na "qual a totalidade extensiva da vida não é mais dada de modo evidente, para a qual a imanência do sentido à vida tornou-se problemática, mas que ainda assim tem por intenção totalidade". (LUKÁCS, 2009, p. 55). Na segunda parte da obra, Lukács analisa os romances dividindo-os em grandes tipologias: o idealismo abstrato, com Dom Quixote e os romances de Balzac; o romantismo da desilusão, com A educação sentimental, de Flaubert; e o romance da aprendizagem, com Os anos de aprendizagem de Wilhelm Meister, de Goethe. Nesse sentido, o legado de Lukács que Antonio Candido e Roberto Schwarz levaram adiante é a compreensão de que a crítica literária está indissociavelmente ligada com a análise social e histórica, fazendo um ajustamento recíproco entre as duas perspectivas, sociológica e estética.

Para Lukács, a relação entre os problemas da forma e os problemas do conteúdo se dá a partir de uma relação dialética e não de uma maneira reducionista, ou seja, a transformação da forma epopeia para a forma romance não é um fenômeno da transformação do conteúdo simplesmente, pois a forma possui as suas próprias exigências. Essa dialética entre forma e conteúdo 
será levada a cabo por Antonio Candido ao longo de toda a sua produção. A análise da adaptação do romance no Brasil, em Ao vencedor as batatas, apresenta também como eixo as relações entre indivíduo e sociedade, entre ideias e mundo, cuja definição na estrutura romanesca foi uma obsessão lukácsiana. Talvez seja possível afirmar que a maior aproximação de Roberto Schwarz da teoria de Lukács ocorre quando critica José de Alencar inúmeras vezes pela contradição entre os elementos do realismo europeu e o descompasso da adaptação da forma europeia no romance Senhora. Quando Lukács define realismo, o tipo é uma das suas categorias importantes - e também o será para Schwarz na análise de Senhora. O tipo "é a síntese particular que, tanto no campo dos caracteres como no campo das situações, une organicamente o genérico e o individual". (LUKÁCS, 2010, p. 160). A criação de personagens verdadeiramente típicos e o predomínio do método narrativo sobre o método descritivo são duas características, por assim dizer, formais da grande literatura realista de ficção. O abandono da tipicidade e a substituição do predomínio da narração, quer pelo "romantismo revolucionário", quer pela literatura de vanguarda, acarretam inevitável prejuízo para o realismo. A sociedade-tipo e o personagem-tipo de Roberto Schwarz seriam a sociedade oitocentista representada no romance de Machado de Assis por meio da volubilidade do narrador Brás Cubas. Nesse sentido, a crítica ao romance de Alencar como dualidade mal engendrada funciona justamente pela fuga ao romance-tipo de Machado de Assis.

Atrelada à noção de tipicidade está a questão da universalidade da forma artística. Para Lukács, a categoria central da estética é a particularidade, cujo funcionamento se dá pela representação simbólica do singular e do universal, ou seja, 
a particularidade na forma artística não exclui a universalidade, entretanto, ela não funciona sob leis abstratas (como aparece na ciência); ela precisa se apresentar em ligação orgânica com a concretude individual dos seres singulares representados na ficção. Daí a fobia de universal de Roberto Schwarz e da visão negativa das influências francesas de Alencar:

Se a famigerada realidade brasileira compromete o universalismo da cultura moderna, pior para a dita realidade, pois a universalidade do processo civilizatório não tolera desvios [...] Ora, elevar a ilusória idiossincrasia local à condição de argumento, e ponto de vista implicado pelo conjunto de que no entanto discrepa, é próprio da "fobia ao universal" que sempre caracterizou o historicismo. Quer dizer, o raciocínio crítico de Roberto é dualista por estar encharcado desta vez de historicismo. (ARANTES, 1992, p. 51).

Antonio Candido, em contrapartida, afirma: “"[...] o grande amor de Aurélia com a vergonhosa transação que põe Fernando à sua mercê, veremos que os seus melhores livros são aqueles em que o conflito é máximo" (CANDIDO, 2012, p. 543). Ou seja, essa contradição no plano do dinheiro e as semelhanças que o drama de Aurélia mantém com o romance de Balzac não parecem tão problemáticos para Antonio Candido como o são para Roberto Schwarz. Apesar de reconhecer o desnível do romance, assim como Roberto Schwarz o faz no seu texto, Antonio Candido aponta, no conjunto da obra de José de Alencar, as contradições como parte de uma "arte mais consciente e bem armada do que suporíamos à primeira vista". (CANDIDO, 2012, p. 548). Roberto Schwarz aponta como são completamente descabidas as aproximações do romance de Balzac com Senhora, no que se refere aos dramas em torno da esfera mundana, do dinheiro e da carreira, e às personagens periféricas, responsáveis pela 
verossimilhança e a cor local. No entanto, para Schwarz, "Alencar não insiste na contradição entre a forma europeia e a sociabilidade local, mas insiste em pô-las em presença, no que é membro de sua classe, que apreciava o progresso e as atualidades culturais" assim como apreciava também "as relações tradicionais, que lhe validavam a eminência”. (SCHWARZ, 2012b, p. 70).

Segundo Schwarz, a duplicidade cor local e forma europeia, arcaico e moderno, emperra o desdobramento da estética realista, pois na tentativa de conciliar os opostos, torna desajustado o romance. No início da análise de Senhora, Roberto Schwarz parte de uma colocação de Antonio Candido a respeito de Joaquim Manuel de Macedo, acerca de uma incongruência característica dos romances dos primeiros românticos: de um lado, o realismo miúdo, fiel às aparências e aos personagens do Rio de Janeiro oitocentista, de outro, a trama extremada do enredo romântico. Para Schwarz, trata-se de uma combinação inverossímil de duas convenções literárias incompatíveis: a primeira obedecendo à descrição do cotidiano brasileiro, a fim de lhe atribuir uma aparência estética; a segunda exigindo a forma do romance europeu, cuja imanência pressupunha uma civilização burguesa e não uma ordem patriarcal e escravocrata. Das marcas literárias frouxas que Antonio Candido apontou em Macedo - de nosso desenvolvimento desigual e combinado, ou seja, de nossa fidelidade aos padrões europeus de comportamento (a cuja ordem nunca deixamos de pertencer) e à ordem local patriarcal -, Roberto Schwarz deu um passo adiante, ao marcar a presença dessa mesma disparidade entre enredo e notação realista na obra de José de Alencar. A conjunção desajustada de matéria local e molde europeu configura uma dualidade com sinal negativo, pois trata-se de um impasse que compromete pela raiz o valor da obra: 
Uma rede de personagens de segundo plano, porém verossímeis em sua estreiteza nacional, acaba desacreditando o conflito central: essa a dualidade formal que inviabiliza Senhora. Porém nada mais brasileiro do que esse defeito de composição. E para melhor ressaltar-lhe o valor mimético, Roberto propositadamente analisa a variação de tom do romance progredindo da "periferia" do livro (singela e familiar) para o seu "centro" (mundano e de alta voltagem moral), como se na forma dual da composição mal resolvida se espelhasse o duplo foco da gravitação mundial de que éramos parte e nos desequilibrava a vida. Na periferia (nos dois sentidos) a vida corre desafogada, "vícios, virtudes e mazelas admitem-se tranquilamente", a prosa que a descreve é balanceada e isenta como a do Sargento de Milícias (se for permitido o palpite), enquanto no centro a linguagem vem saturada de reflexões normativas, bem calcada no figurino europeu da vida complexa. A consonância com o padrão brasileiro não poderia ser maior, só que inteiramente cega por incorporar sem crítica um desajuste que de fato balizava o dia-a-dia ideológico de nossas elites. Vejase então que a má dualidade de Alencar não peca por ser dual, mas por justapor o que a realidade articula, por conjugar sem malícia o que a prática dos abastados alternava perversamente. (ARANTES, 1992, p. 76).

Nessa passagem, Paulo Arantes destaca a visão negativa que Schwarz apresenta do funcionamento da dualidade no romance de José de Alencar. O programa dialético traçado por Antonio Candido, consagrado pela tradição materialista de Lukács, cujo objetivo é encontrar na configuração artística a estrutura social sedimentada, foi levada a cabo por Roberto Schwarz. Entretanto, Schwarz se distancia de Candido ao absorver elementos adornianos da dialética negativa em relação à crítica ao progresso.

A crítica ao progresso é o segundo ponto de divergência entre os dois críticos brasileiros e foi apontado pelo professor Alfredo 
César Barbosa de Melo, em "Pressupostos, salvo engano, de uma divergência silenciosa: Antonio Candido, Roberto Schwarz e a modernidade brasileira (MELO, 2014). Segundo Melo, Candido se mostra, no texto "Dialética da malandragem", mais otimista em relação ao progresso que Roberto Schwarz. Ao mostrar que intelectuais progressistas, como Manuel Antonio de Almeida, em Memórias de um sargento de milícias, estão mais aliados às classes populares, principalmente por meio das peripécias do personagem central Leoardinho, Antonio Candido demonstra como o romance de Almeida faz um retrato mais objetivo do processo social no Brasil. Já Roberto Schwarz analisa "a contrapelo esse discurso dominante", identificando e denunciando certas verdades latentes mas não-ditas dentro do próprio discurso das classes senhoriais no Brasil. O exemplo máximo estaria em Brás Cubas, narrador de Memórias póstumas. Segundo Melo, Schwarz mostra com grande sutileza como Machado de Assis faz da voz de Brás Cubas um instrumento analítico que desnuda as prerrogativas de classe por trás da retórica universalizante do narrador. A verdade de uma sociedade também poderia ser encontrada nas suas elites, não apenas em personagens populares como no caso de Leonardinho: "Uma verdade que nada teria a ver com a confiança no progresso conduzido pelas camadas populares - como no caso de Candido -, mas com a desfaçatez de uma elite que aposta no atraso social como forma de inserção na modernidade". (MELO, 2014, p. 17).

Antonio Candido, em suas diversas críticas a José de Alencar, aponta no autor as contradições da sociedade brasileira como um aspecto positivo: "O drama do jovem sensível em face da sociedade burguesa é, de fato, a contradição entre a necessidade de obter pecúnia e a de preservar as disponibilidades 
para a vida do espírito". Mais adiante, corrobora: "Alencar sentiu muito bem a dura opção do homem de sensibilidade no limiar da competição burguesa". (CANDIDO, 2012, p. 540). Candido, nesse sentido, parece muito mais próximo ao Luckács de "Narrar ou descrever" do que Roberto Schwarz. Nesse texto, Luckács defende que a narração figura cenas e experiências do cotidiano e a função principal deve ser dar conta de um processo social. A figuração do processo social seria a grande diferença entre Tolstói e Zola, por exemplo, conforme a qual o primeiro apresenta o processo, o segundo apenas apresenta uma cena fotográfica da realidade.

Roberto Schwarz, sob um prisma mais pessimista que Antonio Candido, no final do seu ensaio sobre José de Alencar, conclui que as contradições do romance Senhora na verdade coexistem e são "harmonizadas na prática do nosso paternalismo esclarecido" (SCHWARZ, 2012b, p. 70). Nesse sentido, a análise de Schwarz, que encontra também seu próprio viés como leitura inovadora, parece muito mais próxima da crítica ao progresso da Dialética do esclarecimento, de Theodor Adorno, cujo centro gira em torno da crítica ao progresso e da presença do irracional no interior da ordem da civilização burguesa. Para Schwarz, Machado "sem elogiar o atraso ia desqualificando o progresso, do qual aquele fazia parte" (ARANTES, 1992, p. 97). Nesse sentido, segundo Paulo Arantes, é possível detectar dois níveis dialéticos na obra de Roberto Schwarz: o primeiro corresponderia à inspiração materialista das relações entre forma e conteúdo; o segundo corresponderia à relação entre a modernização capitalista europeia e a experiência social brasileira. $\mathrm{O}$ segundo nível da dialética, "concerne à passagem do primeiro Machado, conformista por conveniência, ao romancista moderno da segunda 
fase" (ARANTES, 1992, p. 91), cuja primeira formulação desta dialética de segundo nível estaria no tratamento das "insuficiências do realismo à europeia adotado por Alencar: um conjunto de desajustes entre intriga romântico-liberal e relações sociais locais paternalistas". (ARANTES, 1992, p. 91).

Em última instância, é possível afirmar que, na análise de Alencar, Roberto Schwarz é mais cético que Antonio Candido no que concerne às contradições de Senhora e à crítica ao progresso. Segundo Schwarz, Alencar concilia dois opostos que coexistem em um mesmo plano, sem o tensionamento formal necessário, o que gera o descompasso e a fragilidade formal: "um fato crucial de nossa vida - a conciliação de clientelismo e ideologia liberal - ao mesmo tempo que lhe desconhece a natureza problemática, razão pela qual naufraga no conformismo do senso comum". (SCHWARZ, 2012b, p. 71). Schwarz ainda acrescenta que a contradição das relações de classe entre os indivíduos é um dos efeitos ideológicos essenciais do capitalismo liberal e um dos méritos do romance realista de Balzac, "mas não era o princípio formal de que precisávamos, embora nos fosse indispensável como tema" (SCHWARZ, 2012b, p. 79).

O tensionamento do plano das personagens centrais e das personagens periféricas no romance Senhora, a temática da riqueza, da independência feminina e do dinheiro é de "audácia e complexidade consideráveis, verdade que bem apoiado na Dama das camélias" (SCHWARZ, 2012b, p. 79), ou seja, o suposto universalismo de Alencar, e as contradições burguesas postas a partir das personagens, coloca no centro do romance a coisificação burguesa das relações sociais, um princípio formal que não funcionava para Roberto Schwarz no romance brasileiro oitocentista, pertencente a uma sociedade movida pela 
Uma comparação entre as análises de Antonio Candido e Roberto Schwarz sobre José de Alencar

escravidão. Antonio Candido afirma que essa contradição fez com que Alencar tenha sido capaz de "fazer literatura de boa qualidade tanto dentro do esquematismo psicológico quanto do senso da realidade humana", e, por estender sua obra desde a poesia ao realismo cotidiano, da visão heroica e imaginativa à observação cerrada da sociedade, "é que sua obra tem a amplitude que tem, fazendo dele o nosso pequeno Balzac". (CANDIDO, 2012, p. 548).

Antonio Candido e Roberto Schwarz são representantes da crítica literária de cunho sociológico dialético no Brasil. Se a relação de Antonio Candido com Silvio Romero mantém a dialética da continuidade e da ruptura como pode ser visto em O método crítico de Silvio Romero, as descontinuidades de Roberto Schwarz diante do seu mestre Antonio Candido são mais discretas. Pode-se afirmar que Roberto Schwarz está mais para o marxismo frankfurtiano, sobretudo o de Theodor Adorno, do que para Antonio Candido, que reconhece as influências do $\mathrm{New}$ Criticism e da antropologia inglesa, como afirma em Brigada Ligeira. Em "A importação do romance e suas contradições em Alencar", Roberto Schwarz retoma as contradições dos três Alencares de Antonio Candido, contudo, faz uma crítica mais mordaz que o mestre em relação às influências estrangeiras e às contradições entre matéria local e forma europeia. Talvez não seja exagerado afirmar que Antonio Candido seja mais otimista que Roberto Schwarz em relação ao progresso e à modernização brasileira. Fora isso, a crítica pioneira de Antonio Candido é mesmo nascedouro da de Roberto, que, por seu turno, escolheu também um caminho inovador para tratar do mesmo autor. 


\section{Referências}

ARANTES, Paulo. Sentimento da dialética na experiência intelectual brasileira: dialética e dualidade segundo Antonio Candido e Roberto Schwarz. Rio de Janeiro: Paz e Terra, 1992. ARANTES, Paulo. Sentido da formação: três estudos sobre Antonio Candido, Gilda de Mello e Souza e Lucio Costa. Rio de Janeiro: Paz e Terra, 1997

BARROS E SILVA, Fernando. Fora do lugar comum. Folha de S. Paulo, p. 7-8 São Paulo, 1 jun. 1999, Caderno Mais.

CANDIDO, Antonio. Brigada ligeira e outros escritos. São Paulo: Unesp, 1992.

CANDIDO, Antonio. Os três alencares. In: CANDIDO, Antonio. Formação da Literatura Brasileira. Rio de Janeiro: Ouro sobre azul, 2012.

CANDIDO, Antonio. Crítica e sociologia. In: CANDIDO, Antonio. Literatura e sociedade: estudos de teoria e história literária. São Paulo: T. A. Queiroz, 2000.

CANDIDO, Antonio. Literatura e cultura de 1900 a 1945. In: CANDIDO, Antonio. Literatura e sociedade: estudos de teoria e história literária. São Paulo: T. A. Queiroz, 2000.

CANDIDO, Antonio. O método crítico de Sílvio Romero. Rio de Janeiro: Ouro sobre azul, 2006.

LUKÁCS, Georg. A teoria do romance: um ensaio históricofilosófico sobre as formas da grande épica. São Paulo: Duas Cidades, 2009.

LUKÁCS, Georg. Narrar ou descrever. In: LUKÁCS, Georg. Marxismo e teoria da literatura. São Paulo: Expressão Popular, 2010. 
Uma comparação entre as análises de Antonio Candido e Roberto Schwarz sobre José de Alencar

MELO, Alfredo Barbosa de. Pressupostos, salvo engano de uma divergência silenciosa: Antonio Candido, Roberto Schwarz e a modernidade brasileira. Alea, Rio de Janeiro, v. 16, n. 2, p. 403420, jul./dez. 2014.

SCHWARZ, Roberto. A importação do romance e suas contradições em Alencar". In: SCHWARZ, Roberto. Ao vencedor as batatas. São Paulo: Duas Cidades, 2012a.

SCHWARZ, Roberto. Entrevista com Roberto Schwarz. [Entrevista cedida a] Eva Corredor. Literatura e Sociedade, São Paulo, v. 7 n. 6, p. 14-39, 2002.

SCHWARZ, Roberto. Martinha versus Lucrécia: ensaios e entrevistas. São Paulo: Companhia das Letras, 2012b.

SCHWARZ, Roberto. Sequências brasileiras: ensaios. São Paulo: Companhia das Letras, 1999.

SCHWARZ, Roberto. Um mestre na periferia do capitalismo. São Paulo: Duas Cidades, 2000.

WAIZBORT, Leopoldo. A passagem do três ao um: crítica literária, sociologia, filologia. São Paulo: Cosac Naify, 2007. 